\title{
Orações relativas em Nheengatú ou Ingatú
}

\author{
Relative clauses in Nheengatú or Ingatú
}

Edilson Martins Melgueiro ${ }^{1}$

Ana Suelly Arruda Câmara Cabral ${ }^{2}$

Marci Fileti Martins ${ }^{3}$

DOI 10.26512/rbla.v11i02.28115

Recebido em outubro/2019 e aceito em novembro/2019.

\begin{abstract}
Resumo
A língua Nheengatú (Ingatú), versão modificada do antigo Tupinambá falado no século XVII da costa do estado do Maranhão ao baixo rio Tocantins, estado do Pará, desenvolveu-se como língua franca, sob influência do Português e de falantes de diferentes línguas que a adotaram, seja como primeira língua, seja como língua adicional. Das diversas mudanças ocorridas na história do Tupinambá que resultou no Nheengatú moderno, destaca-se o desenvolvimento de orações relativas decorrentes do contato com o Português. Essas orações relativas apresentam características peculiares de interesse para os estudos linguísticos tipológicos, e de natureza histórica, principalmente por se ter acesso às estruturas do antigo Tupinambá, permitindo a identificação da natureza e direções das mudanças ocorridas. O presente estudo aborda as orações relativas da língua Nheengatú em uma perspectiva descritiva e tipológica, a partir de dados coletados na cidade de São Gabriel da Cachoeira, sede do município de São Gabriel, Amazonas, junto a duas mulheres de origem Baré (Aruák), para as quais o Nheengatú é a língua materna e se apresenta em suas respectivas falas como uma variedade mais conservadora da língua. A descrição orienta-se pela tipologia de orações relativas proposta por Keenan e Comrie (1977, 1979), Keenan (1985), e Givon (1990). Beneficia-se também das contribuições aos estudos tipológicos das orações relativas feitas por Lehmann (1986).
\end{abstract}

Palavras-chave: Relativização. Nheengatú. Tupí-Guaraní. Línguas em contato.

1 Doutorando no Programa de Pós-Graduação em Linguística na Universidade de Brasili, professor permanente do Instituto Federal de Educação de São Gabriel da Cachoeira, Amazonas. edilson.melgueiro@ifam.edu.br

2 Professora titular do Departamento de Linguística, Português e Línguas Clássicas da Universidade de Brasília, Coordenadora do Laboratório de Línguas e Literaturas Indígenas do Instituto de Letras da Universidade de Brasília, Bolsista PQ/1D (CNPq). asacc@unb.br 3 Professora do Mestrado Profissional em Linguística e Línguas Indígenas - PROFLLIND, do Departamento de Antropologia - Museu Nacional - UFRJ. marcifm@gmail.com 


\section{Abstract}

The Nheengatú language, a modified version of the ancient Tupinambá spoken in the 17th century from the coast of the state of Maranhão to the lower Tocantins river, state of Pará, developed as a lingua franca, under the influence of Portuguese and speakers of different Indigenous languages that have adopted it, either as a first language or as an additional language. Among the various changes that occurred in the history of Tupinambá to the modern Nheengatú, the development of relative clauses under the influence of Portuguese, is of interest to typological and historical linguistic studies due to their innovative peculiarities, and especially because of the available reference to the structures of ancient Tupinambá, allowing the identification of the nature and directions of the changes that occurred. The present study addresses the relative clauses of the Nheengatú language in a descriptive and typological perspective, based on data collected in the city of São Gabriel da Cachoeira, headquarters of the municipality of São Gabriel, Amazonas, together with two women of Baré origin, for which Nheengatú is the mother tongue and presents itself as a more conservative variety of the language. The description is guided by the typology of relative clauses proposed by Keenan and Comrie (1977, 1979), Keenan (1985), Givón (1990), and benefits from the contributions to typological studies on relative clauses by Lehmann (1986).

Keywords: Relativization. Nheengatú. Tupí-Guaraní. Language contact.

\section{Introdução}

O presente estudo aborda as Orações Relativas (ORs) na língua Nheengatú (Ingatú). Na literatura sobre o tema, em que se destacam, entre outros, Keenan \& Comrie (1977), Keenan (1985) e Givón (1990), uma OR é caracterizada como uma oração subordinada que funciona como modificadora atributiva de um nome, nome este, cabeça ${ }^{4}$ (antecedente) da OR. O nome cabeça é identificado e delimitado pela OR, que é, caracteristicamente, uma oração restritiva.

O Nheengatú, segundo Rodrigues (1986), é a versão atual do que foi a língua Tupinambá falada na costa do Brasil, nos séculos XVI e XVII. O Nheengatú se alterou paulatinamente nos novos contextos sociais em que passou a ser falada, ao longo do Rio Amazonas e seus tributários. Chamada, inicialmente, de Língua Geral nos séculos XVII e XVIII, posteriormente, ficou conhecida como Nheengatú 'fala boa', expressão usada desde o século XVII, em oposição a Ñe'engaíba 'fala ruim' - usada com referência a línguas distintas do Tupinambá e de seus parentes próximos.

Rodrigues (1986:105) tratando do processo de desenvolvimento do Tupinambá para o Nheengatú, afirma que "as maiores alterações sofridas pelo Tupinambá no processo de tornar-se Língua Geral resultam de uma progressiva simplificação das formas gramaticais, acompanhada de reorganização da construção das frases." Uma dessas mudanças envolve o sistema de relativização,

4 Optamos por usar o termo "cabeça", ao invés de "núcleo", para evitar confusão com o uso deste termo como núcleo da $\mathrm{OR}$ - nome, adjetivo ou verbo. 
já que enquanto o Tupinambá usava a nominalização como estratégia de relativização, ou seja, nomes derivados de verbos em lugar de orações relativas encabeçadas por palavras análogas a "que", "o qual” do Português, o Nheengatú, de acordo com o autor, desenvolveu construções relativas "[...] com um verbo propriamente dito e uma partícula que marca a relação entre esse verbo e o nome principal" (1986:109). Rodrigues observa ainda, que diferentemente do Português, em que o pronome relativo se distribui antes do verbo, no Nheengatú a partícula waá ocorre após o verbo5:

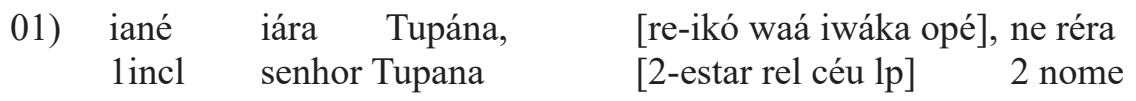

ia-moité ia- ikó. 1incl-honrar lincl estar

"Nosso senhor (iané iára) Deus, que estás no céu, teu nome nós estamos (ia-ikó) [nós] honrando (iamo-ité)."

Nos estudos sobre o Nheengatú, notadamente sobre OR, destacamos o trabalho de Cruz (2011: 510-516), que dedica uma sessão de sua tese de doutorado à descrição de OR na língua. A autora além de reiterar o que já observara Rodrigues (1986), amplia a análise da OR em Nheengatú, apresentando informações sobre posições sintáticas relativizadas. Sobreos tipos de OR, além das externas, a autora propõe também a existência relativas internas, e sem cabeça.

Enquanto Cruz (2011) serviu-se de dados coletados junto a jovens Werekénas, Barés e Baníwas, o presente estudo apoia-se em dados coletados por Cabral, em 2008, na cidade de São Gabriel da Cachoeira, junto a duas mulheres Barés falantes de uma versão conservadora do Nheengatú: a Senhora Josefa (86 anos) e a Senhora Cirila (55 anos). Respectivamente mãe e filha, essas mulheres nasceram e foram criadas na cidade de são Gabriel da Cachoeira e eram falantes do Nheengatú como primeira língua. Os dados foram elicitados com vistas à descrição e análise das ORs em Nheengatú, o que somente agora foi possível ser realizado.

O trabalho que aqui se configura, assim, pretende contribuir com a descrição, análise e documentação do Nheengatú, por meio do estudo das ORs na língua. Essas orações se constituem um caso interessante para os estudos linguísticos ao se desenvolveram a partir de um antigo processo de nominalização de

5 Símbolos e abreviaturas: 1 = primeira pessoa singular; $1 \mathrm{sgA}=$ primeira pessoa singular da série dinâmica; 2 = segunda pessoa singular; 3 = terceira pessoa; 1 incl-primeira pessoa inclusiva; $1 \mathrm{p}=$ primeira pessoa plural; $1 \mathrm{Pe}=$ primeira pessoa do plural exclusiva; $\mathrm{abl}=$ ablativo; $\arg =$ caso argumentativo; ass = associativo; dat $=$ dativo; dem = pronome demonstrativo; ind.II = modo indicativo II; $\mathrm{N}$ = caso nuclear; Nom=nominalizador; ncp $=$ nominalizador de complementos circunstanciais; $\mathrm{np}=$ nominalizador de predicado ; Pas = passado; Pas $/ \mathrm{N}=$ passado nominal; perf = perfectivo; posp = posposição; Loc $=$ locativo; REL = relacional; r2- prefixo relacional de não-contiguidade; rel = relacional; rel $=$ relacional; $r l t=$ relativo; $\operatorname{retr}=$ retrospectivo; $\operatorname{subj}=$ subjuntivo. 
predicados.

\section{Bases tipológicas para a análise}

A análise proposta referencia-se nas tipologias das ORs propostas por Lehmann (1986), Givón (1990) e, sobretudo, por Keenan e Comrie (1977, 1979), e Keenan (1985), propostas estas amplamente conhecidas. A escolha dos referidos modelos de análise se deve ao fato de serem eficientes na identificação de sistemas de relativização em diferentes línguas, os quais podem ser classificados a partir de certos padrões tipologicamente regulares.

Keenan e Comrie (1977) e Keenan (1885) afirmam que as estratégias de formação de ORs se distinguem determinadas por dois critérios: i) a posição do sintagma nominal (cabeça) em relação à OR, e a ii) presença ou ausência de um morfema que expresse a posição relativizada na OR. No que diz respeito ao primeiro critério (posição da cabeça), os referidos autores propõem que as línguas podem apresentar três diferentes tipos: i) pós-nominal, ii) pré-nominal, e relativa interna:

i) OR pós-nominal, a cabeça ocorre à esquerda da relativa:

02) O homem [que chegou] é o professor

ii) OR pré-nominal, a cabeça ocorre à direita da relativa:

03 [Pöydällä tanssinut] poika oli saira [on table having danced] boy was sick "the boy who danced on the table was sick" (Finnish - Keenan 1985:144)

iii) OR interna, em que a cabeça é nula ou fonologicamente não realizado:

04) awuje oro-etsak [o-yk-ama'e-her-a posto-p] já 1Pe-ver 3-chegar-Nom-Pas-N posto-Loc "nós já víamos aquele que chegou no posto" 184)

A outra caraterização proposta por Keenan (1985), que toma como base a posição da cabeça ${ }^{6}$ com relação a OR é a seguinte:

i) OR externa, em que o cabeça se encontra fora da OR:

05) Vi o homem [que comprou o carro de minha mãe]

ii) OR interna em que a cabeça é interna à própria $\mathrm{OR}$ :

$\begin{array}{llll}\text { 06) } & \text { i chuva- } \varnothing \quad \text { tumt-i } & \text { šýikhi? } \\ \text { me house-do bouth-subj } & \text { burned down } \\ \text { 'the house I bought burned down' } & \text { (Wappo - Keenan 1985:162) }\end{array}$

6 A partir dessa classificação as OR internas podem ser consideradas como sendo OR "sem cabeça". 
Comrie (1985:143-144) chama a atenção para o fato de que nas línguas com OR externas, há uma predisposição para OR pós-nominais, enquanto em línguas com verbo inicial, tanto OR pós-nominais quanto pré-nominais podem ser encontradas. Já nas línguas com verbo medial, OR pós-nominais são dominantes, e nas línguas com verbo final, relativas pré-nominais são as únicas ou mais produtivas formas de relativas.

Sobre o segundo critério "a presença ou a ausência" de morfema que codifique a posição relativizada, Keenan (1985) e Comrie (1989) propõem quatro tipos de estratégias de relativização: lacuna, retenção de pronome, pronome relativo e não-redução. Givón (1990), por sua vez, tomando como critério a recuperabilidade de caso para definir as estratégias de relativização, propõe os seguintes critérios: a não-redundância, lacuna, ordem de palavras, nominalização, pronome anafórico, pronome relativo, caso idêntico e codificação do verbo.

A Hierarquia de Acessibilidade (HA) (Keenan e Comrie, 1977, 1979) diferencia tipos de OR a partir da posição sintática do argumento compartilhado pela oração principal (antecedente) e a OR (relativizado). Os autores propõem a seguinte escala que estabelece restrições à acessibilidade das posições sintáticas ai envolvidas:

Sujeito $>$ Objeto Direto $>$ Objeto Indireto $>$ Oblíquo $>$ Genitivo $>$ Objeto de Comparação

De acordo com a escala proposta, a expressão nominal na função de Sujeito, sendo a mais alta na HA, é mais acessível à relativização. Por outro lado, a posição de Objeto de Comparação, situada no lado oposto da escala, é a menos acessível. O princípio restritivo (universal implicacional) que aí se estabelece, aponta o Sujeito como a posição primária para relativização, determinando que se uma língua relativiza a última posição da escala - Objeto de Comparação - vai necessariamente relativizar, também, todas as posições anteriores Embora orientados pela tipologia de Keenan e Comrie (1977), consideramos a advertência feita por Lehmann (1986:669) a respeito da hierarquia de funções sintáticas:

The hierarchy of syntactic functions answers some of the questions that we may ask about the achievement of a RC strategy with regard to relativizable syntactic functions, and that there are others it does not answer" " .

\section{Orações Relativas (restritivas) em Nheengatú}

\footnotetext{
7 “A hierarquia das funções sintáticas responde a algumas das perguntas que podemos fazer sobre a realização de uma estratégia de RC em relação às funções sintáticas relativizáveis, e que existem outras que ela não responder." (Tradução nossa).
} 
As mudanças gramaticais ocorridas do Tupinambá setecentista ao Ñeengatú ao longo de quase quatro séculos, caracterizam-se, por um lado por simplificações fonológicas, morfológicas e morfossintáticas e, por outro lado, por inovações nos diferentes subsistemas linguísticos, embora a língua não tenha perdido características genéticas que fundamentam a sua classificação como uma língua da família Tupí-Guaraní e originária, inequivocamente, do Tupinambá.

Enquanto o Tupinambá, assim como outras línguas Tupí-Guaraní modernas apresentam sufixos nominalizadores de predicados, reflexos do Proto-TupíGuaraní *- $\beta a$ 'é 'nominalizador de predicados', o Nheengatú exibe a partícula waá (do Tupinambá - $\beta a$ 'é). A partícula waá do Nheengatú ocorre após o verbo e parece funcionar como um pronome relativo do português, ou seja, retoma na OR o antecedente que modifica. Além disso, o Tupinambá seiscentista falado em aldeias, era uma língua de verbo final. No Nheengatu, por influência do Português, essa ordem mudou passando a ser aquela com verbo inicial. Contudo, mantém, como ocorria no antigo Tupinambá, as ordens nome-posposição, nome-adjetivo, e possuidor-possuído $($ possuidor $=$ nome $)$.

As ORs do Nheengatú apresentam-se externas ao domínio da cabeça e ocorrem à direita desta, sendo, portanto, pós-nominais, em concordância com a ordem nome-adjetivo da língua (Keenan 1985). Como uma língua com ORs externas, o Nheengatú se adequa à predisposição para ORs pós-nominais (Comrie 1985). A partícula relativizadora waá que segue o predicado da OR, não sustenta a generalização que aponta essa distribuição como típica de línguas com verbo final. No entanto, apresentando waá como uma partícula relativizadora, o Nheengatú pode ser considerado uma língua que usa a estratégia de "pronome relativo" (Keenan 1985; Givón 1990):

07) apigá(wa) [u-síka $\quad$ waá] aé
homem $\quad$ [3-chegar mú(m)
'o homem [que chegou] é meu irmão'

O sintagma nominal (cabeça) omitido na OR é recuperado pela partícula waá. Na situações em que a posição relativizada na ORs é a de sujeito de verbos transitivos e intransitivos, prefixos pessoais no núcleo dos predicados estabelecem uma relação anafórica com a cabeça da OR, como propõe Lehmann (1986). Esse caso, pode ser considerado um outro tipo de estratégia de relativização denominada "retenção pronominal" (Keenan, 1985, e Comrie, 1989):

08) a-meẽ papéra [u-surúka waá] ix-upé

1-dar livro 3-rasgar REL] 3-dat

'eu dei o livro [que rasgou] para ele'

$\begin{array}{llllll}\text { 09) a-yuíri apigá(wa) } & \text { irúmu } & \text { [u-yuká } & \text { waá } & \text { yawára] } \\ \text { 1-vir } & \text { homem } & \text { ass } & {[3 \text {-matar }} & \text { rel } & \text { cachorro] } \\ \text { 'eu vim com o homem [que matou o cachorro]' } & & \end{array}$


No caso em que o objeto é a posição relativizada na OR, não se observa a sua codificação por meio de prefixos pessoais no verbo. A recuperação do antecedente, assim, se efetua pela partícula waá e também pela valência do verbo:

$\begin{array}{llll}\text { apigá(wa) } & {[\text { ha-mã }} & \text { waá }] & \text { u-síka } \\ \text { homem } & {[1 \text {-ver }} & \text { rel }] & \text { 3-chegar }\end{array}$

'o homem, [que eu vi], chegou'

Quando o núcleo do predicado da OR é um nome (11) ou atributo (12), também não se identifica a codificação da posição relativizada, por meio de prefixos pronominais. A não ocorrência de prefixos pronominais nessas ORs segue o padrão estrutural dos predicados que têm por núcleo um nome ou atributo no Nheengatú. Esses predicados não apresentam concordância com o sujeito, seja por meio de prefixos pessoais seja por representantes sintáticos:

11) apigá [médico waá] u-síka.

homem [médico REL] 3-chegar.

'o homem, que é médico, chegou'

12) kurumí [puránga waá] u-síka. menino [bom/bonito Rel] 3-chegar.

'o menino, [que é bonito], chegou'

De fato, em Nheengatú, como em outras línguas da família Tupí-Guaraní, predicados nominais e atributivos podem se constituir apenas por seu núcleo, que é um nome ou um "adjetivo" ${ }^{8}$, respectivamente, que passam a ter, nessa estrutura, a função de verbo. O Tupinambá, como documentado por Rodrigues ([1953] 2010, 1996), tinha como particularidade o fato de seus nomes predicarem. Esse é também o caso do Zo'é (Cabral 2009, 2019), do Araweté (Solano 2009), do Kayabí, do Amondáwa (Cabral, comunicação pessoal), e de muitas outras línguas da família Tupí-Guaraní. Alguns exemplos do Nheengatú com predicados nominais (13) e atributivos (14-15) são os seguintes:

8 A determinação das classes de palavras em línguas Tupí-Guaraní se constitui uma questão de interesse da pesquisa linguística, ao mesmo tempo que se mostra uma questão controversa. Como é sabido, nessas línguas os limites entre as categorias lexicais podem não ser tão claros, o que constitui uma questão complexa e importante para a pesquisa linguística. Enquanto, por um lado, a maioria dos estudos sobre o tema parece ser unânime em aceitar uma classe independente de nome e verbos, por outro, não apresenta consenso na classificação da classe dos adjetivos. Assim, os itens lexicais com características qualificadoras, tais quais adjetivos no Português, são considerados ora como verbos (Kamaiurá - SEKI, 1990/2000/2001), ora como nomes (Tupinambá - RODRIGUES, 2011 [1996]) e línguas TG - DIETRICH, 2001). Outras propostas como a de Martins (Guarani Mbya - 2003, 2007) analisa esses itens atributivos como adjetivos, sendo que a de Queixalós (2006) defende a hipótese que nas línguas Tupí-Guaraní todas as entradas lexicais são predicados - um padrão denominado de "omnipredicatividade". 
13) ixé i-mãya

1 3-mãe

'eu sou mãe dele'

14) ixé turusú

1 grande

'eu sou grande'

15) úka turusú

casa grande

'a casa é grande'

Esse tipo de oração, com predicado nominal, pode ser caracterizada como uma oração equativa, que é um tipo de oração identificadora. Segundo Seki (2000), uma oração identificadora é aquela constituída de dois nominais, sendo que um deles tem função de sujeito e outro a de predicado e correspondem a construções com o verbo ser e estar do Português.

A função predicativa no Nheengatu, portanto, não é uma propriedade apenas de verbos. As expressões nominais e atributivas, núcleos do predicado, ao serem relativizadas, seguem o padrão de codificação dos participantes das estruturas não nominalizadas. Caso exemplar para demonstrar o funcionamento tanto das estratégias de nominalização na língua, quanto das propriedades predicativas de um nome no Nheengatú, é a estrutura (16), em que se observa um sintagma preposicional nominalizado funcionando como predicado nominal da OR:
16) s-úka [táypa suí-uwára
waá] u-káj
3-casa [taipa abl-npc rel] 3-queimar
'a casa dela, que é de taipa, queimou'

O sintagma posposicional táypa suí nominalizado pelo sufixo-uwára passa a função de núcleo do predicado nominal da OR, que ocorre sem a codificação da posição relativizada por prefixos pronominais. Rodrigues ([1981] 2010:16) chamou o cognato desse sufixo em Tupinambá de "nominalizador de complementos circunstanciais", expressão que adotamos neste estudo para denominar o sufixo -uwára do Nheengatú. A posição relativizada nesse caso é a de sujeito de predicado nominal. A recuperação da cabeça relativizada na OR é feita por waá e pela relações sintáticas codificadas pela estrutura equativa.

Contudo, como mostraremos a seguir, há ainda ORs que apresentam outras estratágias de recuperação do antescedente. Numa delas, cujo núcleo do predicado é um nome ou um atributivo, observa-se a ocorrência do pronome demonstrativo ñã. Esse pronome parece estar funcionando como um resumptive pronoun:

17) Pedro [ñã kupixá(wa) yára waá] u-sikã(-na) 
Pedro [dem roça dono Rel] 3-chegar-perf

'Pedro [aquele que é dono da roça] chegou'

Em outras ORs, com o elemento awá, que se distribui como complemento de posposição,também parece funcionar recuperando o antecedente relativizado:

18) pigá(wa) [awa resé ha-manduári waá] u-yuká awára

homem [quem posp 1-lembrar rel] 3-matar cachorro

'o homem [de quem eu me lembro] matou o cachorro'

\section{Posições sintáticas relativizáveis: a Hierarquia de Acessibilidade}

Os resultados da análise dos dados do Nheengatú mostram também, que da Hierarquia de Acessibilidade proposta por Keenan e Comrie (1977), praticamente quase todas as posições podem ser relativizadas na língua. Das funções sintáticas suscetíveis à relativização em Nheengatú podem ser relativizados o Sujeito de verbos transitivos e intransitivos, o Sujeito de predicado nominal ou atributivo, o Objeto Direto, Objeto Indireto, incluindo outros oblíquos e o Possuído em uma construção possessiva:

\section{Sujeito de verbo transitivo}

\begin{tabular}{|c|c|c|c|c|}
\hline $\begin{array}{l}\text { a-yuíri } \\
\text { 1-vir }\end{array}$ & $\begin{array}{l}\text { apigá(wa) } \\
\text { homem }\end{array}$ & $\begin{array}{l}\text { irúmu } \\
\text { ass }\end{array}$ & $\begin{array}{l}\text { [u-yuká } \\
\text { [3-matar }\end{array}$ & $\begin{array}{l}\text { waá } \\
\text { rel }\end{array}$ \\
\hline
\end{tabular}

\section{Sujeito de verbo intransitivo}

20) apigá(wa [u-síka waá] aé medico

homem [3-chegar rel] 3 médico

'o homem, [que chegou], é médico'

21) a-meẽ papéra [u-surúka waá] ix-upé

1-dar livro 3-rasgar rel] 3-dat

'eu dei o livro [que rasgou] para ele'

\section{Sujeito de predicado atributivo}

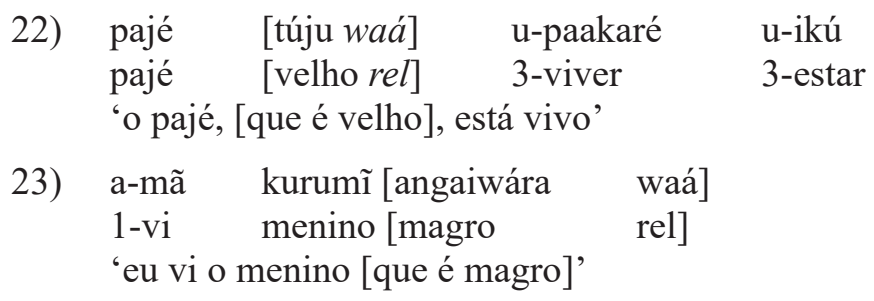

\section{Sujeito de predicado nominal}

24) apigá [médico waá] u-síka.

homem [médico rel] 3-chegar.

'o homem, que é médico, chegou' 
25) María membíra [se prímu waá] u-síka

Maria filho(a) [1 primo REL] 3-chegar

'o filho de Maria [que é meu primo] chegou'

\section{Objeto direto}

26) xirúra [re-meē waá xe aráma] aé puránga

calça [2-dar REL1 para] essa bonito

'a calça [que você deu para mim] é bonita'

\section{Objeto indireto e outros oblíquos}

27) pigá(wa) [awá resé ha-manduári waá] u-yuká awára homem [quem posp 1-lembrar rel] 3-matar cachorro 'o homem [de quem eu me lembro] matou o cachorro'

28) pigá(wa) [awá resé ha-manduári waá] u-yuká awára homem [quem posp 1-lembrar rel] 3-matar cachorro 'o homem [de quem eu me lembro] matou o cachorro'

As ORs (28-29), exemplos relativização de argumentos oblíquos, ocorrem com o elemento awá, que se distribui como complemento de posposição. Awá será analisado a seguir.

\section{A recuperação do nominal relativizado}

Os dados do Nheengatú apresentados mostraram que o nominal relativizado que é omitido na OR, é recuperado pelo partícula waá, e em algumas ORs - aquelas com predicado verbal (posição de sujeito) - também por meio de pronominais prefixados no verbo. As ORs composta por predicados nominais e atributivos, por sua vez, não apresentam marcadores de pessoa que codificam a posição relativizada. Nesses casos, a recuperação do nominal relativizado se dá por meio da partícula relativizadora.

No entanto, há ainda no Nheengatú ORs que apresentam um pronome indefinido awá cujo referente é thumano, e aquelas com predicado nominal e atributivo, que ocorrem com o pronome demonstrativo $\tilde{n} \tilde{a}$, que funcionam, ambos, recuperando o antecedente da OR.

\subsection{O pronome indefinido awá como complemento de posposição em ORs}

A de recuperação do antecedente da relativa pode ocorrer por meio de awá, que se distribui como complemento de posposição. Awá é analisado aqui, como um pronome indefinido cujo referente é thumano, assim desenvolvido em Nheengatú por influência do Português: ${ }^{9}$

9 Em Tupinambá, awá significava 'pessoa, ser humano', e funcionava também como 
'o homem [de quem eu me lembro] matou o cachorro'

30) kuñantãi [awá supé a-meē waá buneka] aé sé sobrinha moça [quem para 3-dar rel boneca] essa 1 sobrinha 'a menina [para quem eu dei a boneca] é minha sobrinha'

Como pode ser observado nos exemplos (30-31), a posição relativizada nessas orações é a de oblíquo: objeto indireto e benefactivo, respectivamente. Nos dados disponíveis, os exemplos de relativização de oblíquo só ocorrem codificada por awá como complemento de posposição. Essa distribuição pode estar indicando que a estrutura - awát posposição - está sendo usada como estratégia para relativização da posição sintática de oblíquo na OR. Contudo, uma análise mais rigorosa se faz necessária, antes de afirmações mais categóricas.

\subsection{O pronome demonstrativo ñã}

$\mathrm{O}$ demonstrativo ñã ${ }^{10}$ marca a posição relativizada (sujeito) na OR com predicado nominal, e parece funcionar como um resumptive pronoun, retomando o antecedente:

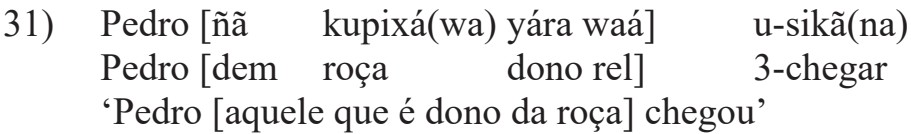

pronome interrogativo. Em Nheengatú, com o desenvolvimento da palavra míra 'gente, pessoa' (de -pir 'pele' e $m$ - 'relacional genérico e humano' = míra), o antigo awá preservou apenas seus traços pronominais, ocorrendo em perguntas e como complemento de posposição. Por outro lado, a contraparte não humana do antigo awá, que era ma'ẽ $\sim$ mba'ẽ em Tupinambá, sofreu evoluções fonológicas em Nheengatú (ma'ẽ > maã), mas preservou suas propriedade de nome, como mostram os seguintes exemplos:

o-páwa arãma iépé maã, katú raín iupyrú

3-acabar para um coisa, bom necessário iniciar

'para acabar uma coisa é necessário iniciar'

kwá kisé se maã

esta faca 1 coisa

'esta faca é meu pertence/coisa'

re-rekú será maã re-muñã arãma?

2-ter duv coisa 2-fazer para?

'você tem alguma cousa a fazer?

10 Cruz (2011: 146-149) distingue pronomes demonstrativos (que se diferenciam pelo parâmetro "distantes versus próximos") e os demonstrativos determinantes: "Poderíamos traduzir as formas aitekua e aitenhaã para o Português coloquial como 'isto aqui' e 'aquele lá'. Isso, porque, estão ligadas aos demonstrativos determinantes kua e nhaã. As formas longas são nomes, ou seja, funcionam como núcleo de sintagma nominal. As formas curtas determinam um nome (v. 6.2.1)." 
32) Migue u-meē kamixá Felipe supé [ñã i-mu waá] Miguel 3-dar camisa Felipe dat [aquele 3-irmão rel] 'Miguel deu camisa para o Felipe, [aquele que é seu irmão]'

33) José u-meē kupixá(wa) Madalena supé [ñã xi-mirikú waá] Jusé 3-dar roça Madalena dat [dem 3-mulher rel] 'José deu a roça para Madalena [aquela que é sua mulher]'

$\mathrm{O}$ uso do demonstrativo ñã retomando o antecedente e codificando-o na $\mathrm{OR}$, não está restrito a casos como os exemplificados em (32-34). Em uma OR, cujo predicado é um atributivo, o pronome demonstrativo também pode ocorrer, sendo que a ordem dos constituintes da oração contendo a cabeça da OR, assim como a própria OR passam a apresentar uma distribuição diferenciada:

$$
\begin{array}{ll}
\text { u-síka [ñã puránga waá], } & \text { kurumĩ } \\
\text { 3-chegar [dem bom/bonito rel] } & \text { menino } \\
\text { 'ele chegou, [aquele que é bonito], o menino. }
\end{array}
$$

A OR (35) contendo um predicado atributivo, ao se diferenciar do padrão das ORs em Nheengatú, as quais são pós-nominais, poderia sugerir, em um primeiro momento, que essa ordem característica seria resultado da ocorrência do demonstrativo ñã junto a predicados atributivos. Contudo, os dados em (3637) inviabilizam esta análise, já que, como pode ser observado, o deslocamento ocorre tanto em estruturas em que a OR contém um predicado nominal (36), quanto naquelas sem o demonstrativo ñã (37):

35) [ñã kupixá(wa) yara waá], Pedro, u-sikã(+na)

[dem roça dono rel] Pedro 3-chegar(+perf)

'[aquele que é dono da roça], Pedro, chegou'

36) [sé prímu waá], Maria membíra, u-síka

[1 primo Rel] Maria membira 3-chegar

'[o que é meu primo], filho de Maria, chegou'

Além disso, no que diz respeito à generalização de Keenan (1985:147) uma OR com predicado que tem como núcleo um adjetivo implica a ocorrência de um pronome ${ }^{11}$ - não se sustenta para o Nheengatú, pois como já apresentado, quando o núcleo do predicado da OR é um nome ou atributo não se observa a codificação da posição relativizada por meio prefixos pronominais: a OR segue o padrão estrutural dos predicados que têm por núcleo um nome ou atributo na língua.

11 Exemplos do Hebreu apresentados por Keenan (1985:147):

“18) a. ha-ish she-hu meod xaxam the-man that-he very smart 'the man who is very smart'

$\begin{array}{lll}\text { b. *ha-ish } & \text { she meod xaxam } \\ \text { the-manthat very smart" }\end{array}$ 
O que os dados evidenciam é que distribuição do demonstrativo ñã se restringe às orações ORs com predicados nominais e atributivos. Nessa estruturas em que não há a codificação das posições sintáticas por pronominais, o demonstrativo pode ser uma estratégia da língua para a recuperação da cabeça na OR. Contudo, uma análise mais rigorosa desses dados deve ser feita, para que se possa compreender a aparente opcionalidade tanto do demonstrativo ñã quanto da distribuição OR que se diferencia do padrão aparentemente não marcado da ordem das relativas no Nheengatu, que é pós-nominal.

\section{Relativas sem cabeça (livres) em Nheengatú ou resquício da nominalização}

Cruz (2011) em sua análise das ORs propõe a existência, no Nheengatú, de ORs sem cabeça (livres). Um dos exemplos dados pela autora é aqui, reproduzido com a numeração original:

a- $\quad$ kua [a- nheẽ waa]

1sgA-saber 1sgA-dizer REL

'Sei o que digo.'

Rodrigues ([1953] 2010:82) tratou $\beta a$ 'é como um 'sufixo relativo', formador de um nome relativo, equivalente à oração relativa com sujeito de terceira pessoa. Em seu estudo de 1981, chama esse sufixo de 'nominalizador de predicados'. Construções com $\beta a$ 'é funcionam como núcleo de predicados nominais, como observa Anchieta (1990:82):

Na construção da frase, sempre o sujeito se pospõe a ele, principalmente quando é predicativo, complemento de sou, és, é..., como ojukábae ixé eu sou o que mata, e é o mesmo que jukására ixé.

A natureza nominalizadora do morfema Tupí-Guaraní ßa'é é também evidente em línguas conservadoras da família, como o Asuriní do Tocantins:

37) i-moná-wa'é o-sekýj

$\mathrm{R}^{2}$-roubar-np 3-morrer

'o ladrão morreu'

(Cabral e Rodrigues 2003:30)

38) i-pitíng-wa'é-kwér-a i-pihón

$\mathrm{R}^{2}$-branco-np-retr-arg $\quad \mathrm{R}^{2}$-escuro

'era branco, agora é escuro' (Cabral e Rodrigues 2003:74)

39) ewokwé i-tór-i o-són-wa'é a-há

eis lá $\quad \mathrm{R}^{2}$-vir-indII 3-vir-np 3-ir

'lá vem o que corre' ～(Cabral e Rodrigues 2003:134) 
Note-se que, em Asurini do Tocantins (38-40) - como em Tupinambá e em outras línguas conservadoras da família Tupí-Guaraní - predicados (verbais, nominais, atributivos) nominalizados pelo "nominalizador de predicado", podem, como qualquer nome, exercer funções sintáticas tanto de argumento quanto de modificador nominal. De tal modo, em estruturas tais como (41) do Asurini do Tocantins, o predicado nominalizado por wa'e pode a funcionar como um modificador nominal:

40) majtinínga h-ahý-wa'é jararáka $\quad \mathrm{R}^{2}$-dor-np 'jararaca venenosa' ou 'é a que tem veneno' (Cabral e Rodrigues 2003:10)

O fato de as construções com waá em Nheengatú ocorrerem como complemento de verbos transitivos tal qual o exemplo (1063), extraído de Cruz (2011) é, muito provavelmente, a retenção de um antigo padrão da língua Tupinambá. Embora o antigo nominalizador - $\beta a$ 'é do Tupinambá tenha evoluído para uma partícula em Nheengatú, a língua pode ainda estar guardando resquícios do nominalizador original.

De fato, Martins (2003/2019) mostra que no Guarani Mbya, as ORs com $v a$ 'e também apresentam uma distribuição diferenciada daquela das línguas mais conservadoras. Para a autora, a relativização com va'e no Guarani Mbya, apresenta dois tipos de estratégias:

1) Uma, a mais comum nas línguas $T G$, envolve a nominalização da oração relativizada, em que -va'e é um sufixo nominalizador/relativizador:

42) o-vae ava [o- $\phi$-poi-va'e-gue guira'i pe]

3-chegar homem [3-3-soltar-Nom/Rel-Pas/N passarinho Pos]

"Chegou o homem que soltou o passarinho"

2) Na outra, a estrutura relativa não sofre nominalização, e o elemento $v a$ 'e comporta-se como uma partícula relativizadora:

43) a- $\phi$-exa avai'i [o- $\phi$-poi guyra'i pe va'e]

1-3-ver menino 3-3-soltar passarinho Pos Rel

"Vi o menino que soltou o passarinho"

De tal modo, mesmo considerando a nominalização como uma estratégia de relativização, o que a distingue da análise de Cabral e Rodrigues (2003) para o Asurini do Tocantins, a proposta de Martins ((2003/2019) é argumento para corroborar a suposição que dois tipos de relativização - uma mais conservadora (waá nominalizador) e outra inovadora (waá relativizador) - podem estar ainda coexistindo no Nheengatú.

\section{Concluindo}


O estudo aqui desenvolvido, a partir dos dados disponíveis, confirma as primeiras observações de Rodrigues sobre as características da ORs do Nheengatú: a maioria das ORs são externas e pós-nominais (Keenan \& Comrie, 1977; Givon 1990). As estruturas nas quais a OR ocorre pré-nominalmente (35-37) necessitam ser melhor investigadas para que se determine as possíveis motivações para tal ordem, aparentemente, marcada.

O nominal (cabeça) é omitido na OR e a recuperação de sua posição sintática é feita por meio da partícula waá, o que pode ser considerado como uma estratégia "de pronome relativo" (Keenan \& Comrie, 1977, Givon, 1990). O relativizador waá que é reflexo do antigo sufixo nominalizador de predicados $\beta a$ 'é do Tupinambá, ilustra, no Nheengatú, uma singular inovação no que diz respeito às estruturas subordinadas na família Tupí-Guaraní. Essa inovação pode ser observada no Guarani Mbya (Martins 2003, 2019), e no Émérillon (Rose 2003) $^{12}$. De tal modo, línguas dos Ramos II, I e VIII, respectivamente, em contextos sociolinguísticos diferenciados, apresentam desenvolvimento análogo, embora todas essas línguas tenham sofrido interferências do contato com o Português e/ou Espanhol, ou com o Francês, no caso do Émérillon.

Dentre as estratégias de recuperabilidade de caso (Givón 1990), o Nheengatú, além da estratégia de "pronome relativo" (partícula waá) também utiliza a de i) "retenção pronominal" (Keenan (1985) e Comrie (1989) em ORs com predicado verbal, que se caracteriza pelo uso de prefixos pessoais no predicado correferenciais ao nominal relativizado, e a de ii) "pronome anafórico" (Givón, 1990). Neste último caso, a codificação do antecedente na OR se realiza de dois modos: i) pelo pronome indefinido awá, que se distribui como complemento de posposição ( $a w a ́+$ posposição), e ocorre codificando a posição de oblíquo, e, por meio do ii) demonstrativo ñã, que é marginalmente opcional em ORs que têm por núcleo um nome ou um atributivo.

Quanto a HA (Keenan \& Comrie, 1977, 1979), são relativizáveis no Nheengatú as posições de sujeito, objeto direto, objeto indireto, outros oblíquos. Sendo que somente a posição de possuidor e objeto de comparação não é relativizável, o Nheengatú, assim, pode ser classificado como uma língua consideravelmente acessível à relativização.

12 “Quant au clitique ma'e de l'émérillon, ... il est utilisé pour relativiser différentes positions telles que sujet, objet, objet de postposition et génitif ainsi que pour introduire des propositions complétives. Concrètement, les propositions introduites par ma'e remplacent tous les autres types de nominalisations. (ROSE 2003:528). "Quanto ao clítico ma'e do Émérillon, ... é usado para relativizar diferentes posições, como sujeito, objeto, objeto de posposição e genitivo, além de introduzir orações complementadoras. Concretamente, as orações introduzidas por ma'e substituem todos os outros tipos de nominalizações." (Tradução nossa) 


\section{Referências bibliográficas}

Cabral, A. S. A. C. 2007. As Categorias Nome e Verbo em Zo'é. In: Cabral, A. S. A. C.; Rodrigues, A. D. (Org.). Línguas e Culturas Tupí. Campinas: Curt Nimuendajú, v. I, p. 241-257.

Cabral, A. S. A. C. Rodrigues, A. D. 2003. Dicionário Asuriní do Tocantins - Português. 1. Ed. Belém, PA: UFPA/IFNOPAP e UnB/IL/LALI, v. 1. 267p..

Comrie, B. and Keenan Edward L.. 1979. Noun Phrase Accessibility Revisited. Language, Vol. 55, No. 3: 649-664.

Cruz, Aline da. 2011. Fonologia e Gramática do Nheengatú: A língua geral falada pelos povos Baré, Warekena e Baniwa. Tese de Doutorado. Vrije Universiteit Amsterdam.

Gimenez, A. D. \& Oliveira, Gabriela. 2010. Descrição tipológico-funcional da oração relativa nas línguas nativas da Amazônia. Estudos Linguísticos, São Paulo, 39 (1): p. 108-118.

Lehmann, Christian. 1986. On the typology od Relative Clauses. Linguistics 24(4):663680.

Keenan, Edward L. 1985. Relative clauses. In Language Typology and Syntactic Description, vol. II: Complex Constructions, ed. by Timothy Shopen, 141-70. Cambridge University Press.

Keenan, Edward L. and Bernard Comrie. 1977. NP accessibility and universal grammar. Linguistic Inquiry 8.63-100.

Martins, M. F. 2003. Descrição e Análise de Aspectos da Gramática do Guarani Mbyá. Tese de Doutorado. IEL. UNICAMP.

Martins, M. F. 2019. Nominalização versus Relativização no Guarani Mbya: uma análise diacrônica do morfema va'e. (No prelo).

Rodrigues, A. D.. 2010. A estrutura do Tupinambá. In: Cabral, A. S. A.C.; Rodrigues, A. D. (Org.). Línguas e Culturas Tupí 2. Campinas, SP: Curt Nimuendajú; Brasília, DF: LALI/UnB, 2010. p. 167-203.

Rodrigues, A. D. 1996. Argumento e Predicado Em Tupinamba. Boletim da Associacao Brasileira de Linguística, v. 19, p. 57-66.

Rodrigues, A. D. [1953] 2010. Morfologia do Verbo Tupí. In: Revista Brasileira de Linguística Antropológica, vol. 3, n. 1:63-86.

Rodrigues, A. D. 1986. Línguas Brasileiras. Para O Conhecimento das Línguas Indígenas. São Paulo: LOYOLA, 1986. v. 1.

Rose, F. 2003. Morphosyntaxe De L'emerillon: Langue Tupí-Guaraní de Guyane française. Thèse pour obtenir le grade de Docteur. Université Lumière Lyon 2.

Seki, L. 2000. Gramática do Kamiurá. Língua Tupí-Guaraní do Alto Xingu. Editora da Unicamp. SP.

Solano, Eliete de J. B.. Descrição Gramatical da Língua Araweté. 2009. Tese Doutorado em Linguística - Universidade de Brasília. 